\title{
Thermoporosimetry of hard (silica) and soft (cellulosic) materials by isothermal step melting
}

\author{
Thad C. Maloney
}

Received: 10 October 2014/ Accepted: 17 February 2015/Published online: 27 March 2015

(C) The Author(s) 2015. This article is published with open access at Springerlink.com

\begin{abstract}
In this study, the pore size distribution of silica aerogels is measured with thermoporosimetry and compared with results from cellulosic materials. The isothermal step melting method is shown to be a useful method to eliminate thermal lag and measures relatively large pores which have a small melting temperature depression. It is shown that for porous silica, pore volumes can be accurately measured by isothermal step melting and that pore diameter can be calculated from the Gibbs-Thomson equation. The nonfreezing water is found to be a monolayer on the pore wall, indicating that hydrated surface area may be probed with this method. The isothermal step melting method is also shown to be very useful to measure pore size distribution of cellulosic materials. However, the Gibbs-Thomson constant for cellulosic materials is markedly different than for porous silica. The pore size distribution for Kraft pulp fibers and for two types of nanocellulose is reported.
\end{abstract}

Keywords Cellulose Nanocellulose Pore

Porosimetry $\cdot$ Thermoporosimetry $\cdot$ Swelling

\section{Introduction}

Thermoporosimetry is a type of pore analysis which is based on the fact that an absorbate held in a porous material will have a depressed melting point [1]. The basic principle is that the known relationships between the pore size and the melting temperature depression, and the pore

T. C. Maloney $(\bowtie)$

Department of Forest Products Technology, Aalto University, PO Box 16300, 0076 Espoo, Finland

e-mail: thaddeus.maloney@aalto.fi volume and melting enthalpy can be exploited to determine the pore size distribution (PSD). A differential scanning calorimeter (DSC) can be used to carry thermoporosimetric measurements. Although other thermal transitions, such as freezing, can be used as a basis for thermoporosimetry, this paper is restricted to melting transitions in aqueous systems.

Thermoporosimetry has been used to measure the PSD of many kinds of mesoporous materials such as ridged inorganic materials $[2,3]$ and soft polymer matrix materials [4-9]. Many thermoporosimetric studies are based on a continuous methodology in which a sample is heated at a constant rate over the melting transition. This approach necessitates compensation of the thermal lag in the system and deconvolution of overlapping transitions in the case where the pore water peak and the bulk water peak are close together. These can be difficult issues, especially for fibrous cellulosic materials that have low heat transfer and overlapping pore and bulk water melting transitions. A good way to solve this problem is by using isothermal step melting. In this method, the temperature is increased in steps. At the end of each step, the temperature is held constant until the melting transition reaches equilibrium. In Fig. 1, the parameters that define a step program are shown: the step interval, $\Delta T$ in ${ }^{\circ} \mathrm{C}$; the heating rate, $\beta$ in ${ }^{\circ} \mathrm{C} \min ^{-1}$; the length of the isothermal segment, $\Delta t_{\text {iso }}$ in min; and the length dynamic segment, $\Delta t$ in min. While this approach solves the problem of thermal lag, it adds the complicating factor that part of the melting takes place in each of the dynamic and the isothermal parts of the program. Therefore, suitable adjustment of the measurement program and a procedure for measuring peak melting enthalpy are required.

The relationship between pore size and melting temperature depression can be described with the well-known 


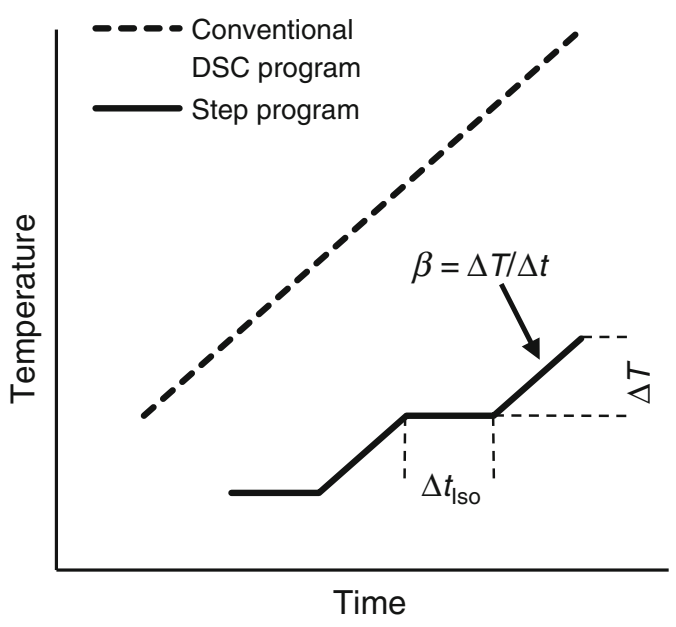

Fig. 1 A conventional (dynamic) and isothermal step program, with the parameters used to define the program indicated

Gibbs-Thomson equation. This is shown for the case of completely wetted cylindrical pores in Eq. 1

$D=\frac{4 V_{\mathrm{m}} \sigma_{\mathrm{ls}}}{H_{\mathrm{m}} \Delta T_{\mathrm{m}}}$

where $D$ is the pore diameter in $\mathrm{m}, V_{\mathrm{m}}$ is the molar volume in $\mathrm{m}^{3} \mathrm{~mol}^{-1}, \sigma_{\mathrm{ls}}$ is the tension at the ice water interface in $\mathrm{J} \mathrm{m}{ }^{-2}, H_{\mathrm{m}}$ is the melting enthalpy in $\mathrm{J} \mathrm{mol}^{-1}$, and $\Delta T_{\mathrm{m}}$ is the melting temperature depression in ${ }^{\circ} \mathrm{C}$. Since $\sigma_{1 \mathrm{~s}}$ is difficult to determine independently, it is more useful to use Eq. 2

$D=\frac{k}{\Delta T_{\mathrm{m}}}+t_{\mathrm{NFW}}$,

where $k$ is the Gibbs-Thomson coefficient in $\mathrm{nm}{ }^{\circ} \mathrm{C}$ and $t_{\mathrm{NFW}}$ is the thickness of the nonfreezing water layer in $\mathrm{nm}$. In this approach, $k$ is determined through calibration against a known pore analysis method: usually mercury intrusion or $\mathrm{N}_{2}$ sorption. Equation 2 also takes into account the fact that a layer of water at the pore interface $\left(t_{\mathrm{NFW}}\right)$ will not freeze and should be accounted for when measuring the PSD.

There have been a number of studies showing the applicability Gibbs-Thomson equation to porous materials $[2,10]$. Such studies are often done with porous glass samples of sufficiently small pore size that the melting peak is completely resolved from the bulk melting peak. Indeed, in these well-behaved systems, Gibbs-Thomson seems to apply and thermoporosimetry can be carried out even using simple continuous methods. However, the applicability of Gibbs-Thomson and the usefulness of thermoporosimetry for more complex materials are still in need of further research.

Cellulose is a polysaccharide consisting of $\beta(1 \rightarrow 4)$ linked D-glucose units. Cellulosic materials comprise a vast category of natural or regenerated polymeric materials where cellulose is a major component. Kraft pulp fibers (cellulose I), regenerated textile fibers (cellulose II), and various types of micro- and nanocelluloses are common examples of industrially important cellulosic materials. In fact, cellulose is the most abundant polymer on the planet and is intensely researched as a sustainable solution in both material and energy applications.

Many cellulosic materials exist in a hierarchical structure where cellulose polymer chains organize into fibrils, which are combined into larger fibril aggregates which in turn are the building blocks of macroscopic fibers. Other plant polymers, such as pentoses and lignin, often play a substantial role in the very complex morphology of cellulosic fibers. The porous structure of cellulose is extremely important in many processing and end use applications. This includes enzymatic hydrolysis [11], chemical modification [12], fiber swelling [13], and rheology [14]. Of particular interest today is an emerging class of "nanocelluloses" [15-18]. Micro- and nanocelluloses are produced by grinding or otherwise defibrillating pulp fibrils into individual fibrils or fibril aggregates. Nanocelluloses are typically from 3 to $100 \mathrm{~nm}$ in diameter and several micrometers in length, while most traditional pulp fibers are in the range $10-100 \mu \mathrm{m}$ diameter and $1-5 \mathrm{~mm}$ in length.

Compared with silica aerogels, cellulose has a very different pore structure. While the pores in silica exist when the sample is dry and thus can be measured with classical pore analysis techniques, cellulose is a hydrogel and must be measured in the water swollen state (aerogels from cellulose can be prepared under special conditions). A second important point is that silica is a hard porous material, so that the pore space does not expand during freezing (unless the material ruptures), and the ice crystal size in the frozen state reflects the pore size in the liquid state. Cellulose, on the other hand, is a soft porous material that can expand and dehydrate during freezing. Thirdly, the pore geometry of silica and cellulose fibers is very different. The pores in porous silica or controlled porous glasses are concave and include a large number of bottlenecks. Many of the pores in cellulose fibers are essentially spaces around fibrils and are convex and highly connected (Fig. 2). Pores within the fibril aggregates or within the hemicellulose cell on the fibril surface are a second category of cell wall pores.

Thermoporosimetry is a very powerful analysis tool for cellulosic materials for a number of reasons. For one thing, it allows measurement of water-saturated samples over a range of moisture contents from the saturated to the dry state. This allows one to examine the consolidation and collapse of pores as a sample is dried. Secondly, thermoporosimetry can give quite a bit of information about the 


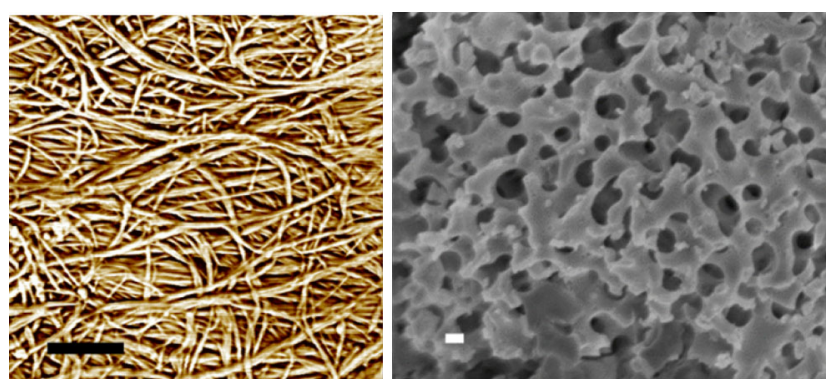

Fig. 2 On the right, an atomic force micrograph of the outer cell wall of a Kraft pulp fiber showing the fibrillar structure. On the left, a scanning electron micrograph of a sample of controlled porous glass (CPG 200). The scale bar in each image is $200 \mathrm{~nm}$

pore size, surface area, and other factors rather quickly-if only the raw DSC data can be properly interpreted. And, finally, the swelling of some types of cellulosic materials (e.g., nanocellulose [19], early- and late-wood cells [4]), which are not easy to measure with other methods can be measured with thermoporosimetry.

In this paper, the use of the isothermal step melting method for measuring well-characterized porous silica and controlled porous glass samples is described. The method is then extended to cellulosic materials, and the PSD for Kraft pulp fibers and two types of nanocellulose is determined.

\section{Materials}

A series of four high-purity silica gel $\left(\mathrm{SiO}_{2}\right)$ samples with nominal pore sizes of 4-15 nm were obtained from SigmaAldrich. Controlled porous glass (CPG) samples with nominal pore diameters from 7.5 to $300 \mathrm{~nm}$ were obtained from CPG Inc. Compared with the silica samples, these have a narrow PSD. All the silica and CPG samples were washed twice in distilled water followed by warm acetone, which was evaporated at $150{ }^{\circ} \mathrm{C}$. The porous glass samples are referred to by either "silica" or "CPG" followed by the nominal pore diameter in nanometers.

A sample of thermo-mechanically produced wood pulp (TMP) is used in some examples to illustrate the isothermal step melting procedure.

A commercial unrefined, never dried, Kraft birch pulp (BHW) is evaluated. The pulp's acid groups were adjusted to the $\mathrm{Na}^{+}$form as described in [19]. Two samples of "nanocellulose" were produced from the BHW pulp. Microfibrillated cellulose (MFC) was produced by grinding the BHW with a Masuko grinder as described in [19]. A sample nanofibrillated cellulose (NFC) was produced by oxidizing the cellulose in the TEMPO process [17] to introduce anionic charge and swell the fibers before grinding.
This process results in a finer material with a higher swelling compared with the MFC.

\section{Methods}

\section{Reference porosimetry}

The PSD and/or pore volume of the silica, GPG and cellulosic samples were determined with certain established reference methods in order to calculate the needed GibbsThomson coefficients and to compare with the results from thermoporosimetry. The methods used were mercury intrusion, $\mathrm{N}_{2}$ adsorption followed by the application of the BET model and solute exclusion.

The solute exclusion method is the least known of these techniques and will be further commented here. This method was originally developed [20] for the determination of the swelling and PSD of pulp fibers. In the method, a dextran polymer of known molecular mass (and thus diameter) is added to a wet pulp sample. The dextran can penetrate into the cell wall into pores that are bigger than itself, and the water inaccessible to the dextran can be determined by careful measurement of the concentration of dextran before and after addition to pulp fibers. By using a range of probes from glucose to $2 \times 10^{6}$ Dalton dextran (corresponding to $0.8-54 \mathrm{~nm}$ Stokes diameter), a PSD in this size range can be determined. A single measurement with a dextran which is too large to penetrate into the cell wall $\left(2 \times 10^{6}\right.$ Dalton dextran) is used to determine the pore volume or fiber saturation point (FSP) of wet pulp fibers. Further discussion of the method can be found in [20] and more recently in [11].

\section{DSC measurements}

The DSC measurements were made on a Mettler $821^{\mathrm{e}}$ DSC equipped with an intracooler. The software included with the instrument was used to process the results. The aluminum samples pans were heat-treated at $500{ }^{\circ} \mathrm{C}$ to form a protective oxide layer on the surface.

Samples were prepared by adding $2 \mathrm{mg}$ of porous glass sample to a $40 \mu \mathrm{L}$ aluminum pan and then adding slightly more water than required to fill the pores. The pan was sealed and allowed to equilibrate overnight. The mass was checked before and after the DSC measurements to ensure that the pan was well sealed. The water content of the glass samples was determined by drying overnight at $150{ }^{\circ} \mathrm{C}$ and cooling over a zeolite desiccant before weighing.

The cellulose samples were prepared by adjusting the moisture content of the samples to $2-3 \mathrm{~mL} \mathrm{~g}^{-1}$ in the case of the BHW and $5-7 \mathrm{~mL} \mathrm{~g}^{-1}$ for the nanocellulose 
samples. The preferable moisture content for cellulose fiber samples is in the range of $1-3 \mathrm{~mL} \mathrm{~g}^{-1}$ to achieve good precision. However, nanocellulose samples should be measured at higher moisture content, preferably over $5 \mathrm{~mL} \mathrm{~g}^{-1}$ in order to avoid the effects of interfibril pores. Further discussion on this effect is found in [19]. A total of 5-10 mg samples of wet cellulose samples were sealed in aluminum pans for measurement. The cellulose samples were dried after DSC measurements at $105{ }^{\circ} \mathrm{C}$ to determine moisture content.

\section{Results}

Melting of water and calibration

Distilled water will be used to illustrate the step melting procedure and to show the method of calibration. A water sample melted dynamically at different heating rates is shown in Fig. 3. The same sample melted with a step program is shown in Fig. 4 expressed as a function of time. In the program used for water calibration, $\beta=0.01{ }^{\circ} \mathrm{C} \mathrm{min}-1, \Delta T=0.02{ }^{\circ} \mathrm{C}$, and $\Delta t_{\text {iso }}=15 \mathrm{~min}$ over the main part of the melting transition.

The choice of parameters depends on the particular sample. Samples which display a high amount of melting in a short temperature interval should have a small $\Delta T$ to give good resolution, a long $\Delta t_{\text {iso }}$ to reach equilibrium, and a low $\beta$ to reduce disturbances when the program changes from isothermal to dynamic mode and vice versa. In some cases, equilibrium is approached very slowly, so it is not practical to allow very long isothermal segments. Figure 4 shows that this is the case when water approaches $0{ }^{\circ} \mathrm{C}$. It makes only a small error in the analysis if equilibrium is not completely reached near the maximum of the melting transition.

In Fig. 5, the sample curve is expressed as a function of sample temperature, $T_{\mathrm{s}}$. The temperature at which all the

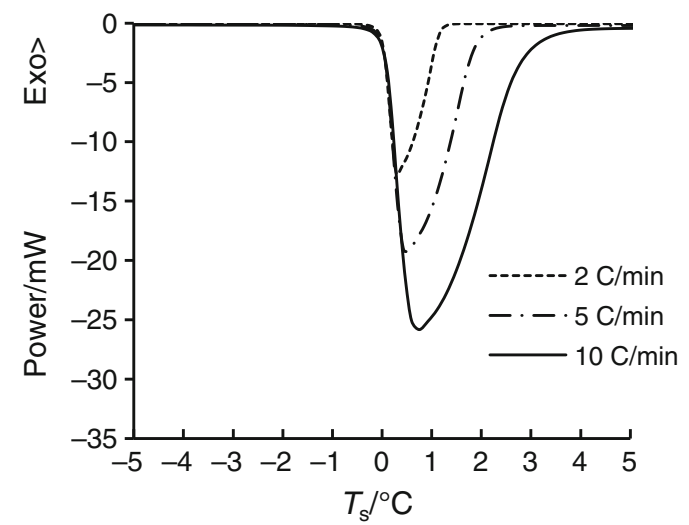

Fig. 3 The melting peak for distilled water measured with a dynamic program at different heating rates

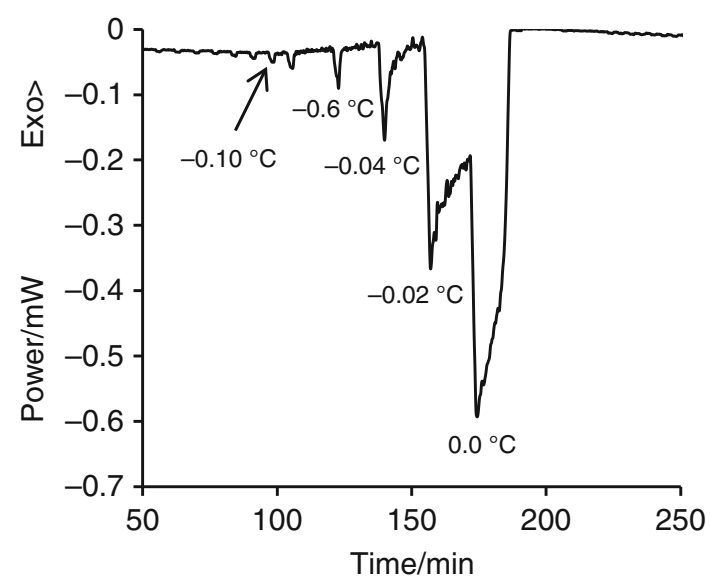

Fig. 4 The melting of distilled water with a step program as a function of time. Same sample as Fig. 3

melting is complete $\left(T_{\mathrm{c}}\right)$ is used for temperature calibration. In this study, three water samples were initially measured. These had $T_{\mathrm{c}}=-0.02,-0.02$, and $-0.04{ }^{\circ} \mathrm{C}$. The internal calibration of the instrument was adjusted by $+0.03{ }^{\circ} \mathrm{C}$, and the same samples were remeasured, and $T_{\mathrm{c}}=0.00,0.00$ and $0.00{ }^{\circ} \mathrm{C}$. A check at the end of the experiments found $T_{\mathrm{c}}=0.02{ }^{\circ} \mathrm{C}$. The author's experience to date indicates that this method of calibration yields a temperature precision and accuracy of about $\pm 0.02{ }^{\circ} \mathrm{C}$. The enthalpy calibration was done by melting three water samples at $\beta=5{ }^{\circ} \mathrm{C} \mathrm{min}-1$ and adjusting the calibration to the standard value of $334.5 \mathrm{~J} \mathrm{~g}^{-1}$. The precision of melting enthalpy for water is $2-3 \%$ and the accuracy $5-6 \%$.

A two-point enthalpy and temperature calibration was done with mercury (melting point $=-38.83{ }^{\circ} \mathrm{C}$ ) and water to roughly calibrate over the temperature range of the experiment. Following this, a single-point enthalpy and temperature calibration was redone with water. This procedure ensures that the melting temperature and enthalpy have a high accuracy at $0{ }^{\circ} \mathrm{C}$.

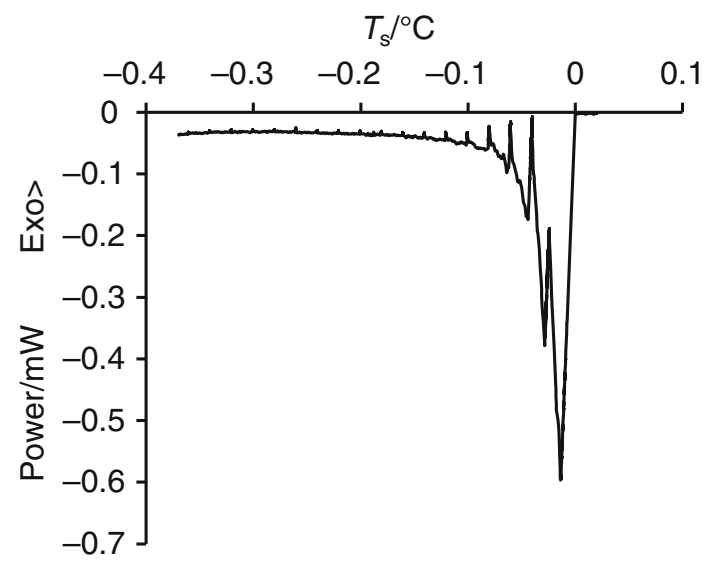

Fig. 5 The melting of water with a step program as a function of temperature. Same measurement as Fig. 4 


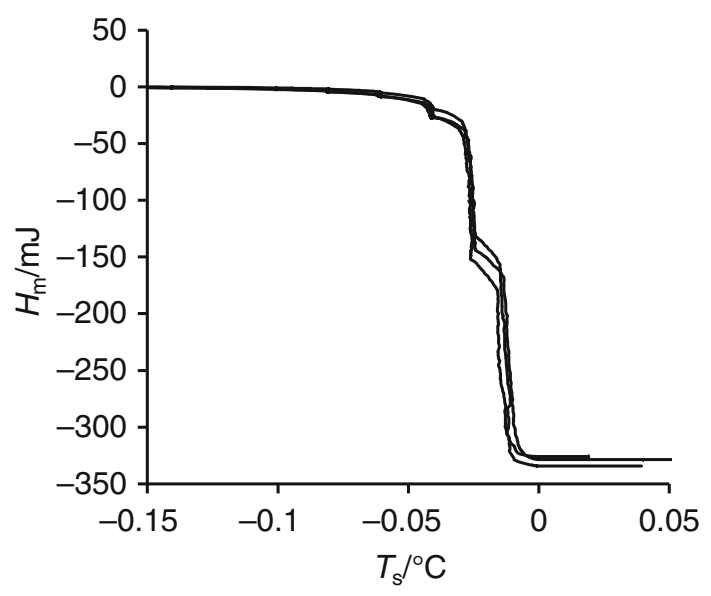

Fig. 6 The enthalpy plots of three water melts with step melting (separate samples), Endothermic transitions are indicated with a negative sign

The melting enthalpy when plotted as a function of $T_{\mathrm{s}}$ for the three water samples after calibration is shown in Fig. 6. The repeatability is clearly very good. Using the step procedure, melting of bulk water is shown to be a nearly isothermal event. However, Figs. $4-6$ do show that there is a small degree of melting just before $0{ }^{\circ} \mathrm{C}$. For practical purposes, the temperature at which appreciable melting of water begins can be defined at $-0.10{ }^{\circ} \mathrm{C}$. Water held in pores must be depressed at least this amount in order to be evaluated by the method. This defines the maximum size of the pores which can be measured with this procedure.

An experiment was performed to determine whether the magnitude of $\beta$ in a step program has any bearing on the temperature or the measured specific melting enthalpy, $H_{\mathrm{m}}^{\prime}$. The results in Table 1 show that $T_{\mathrm{c}}$ and $H_{\mathrm{m}}^{\prime}$ are independent of $\beta$. Furthermore, Table 1 shows that the enthalpy measured in a step experiment is nearly equivalent to that measured dynamically. The melting temperature measured from the onset of a dynamic endotherm is the usual way to define melting point in DSC. As Table 1 shows, this is a different quantity than the isothermal melting point. The onset melting temperature depends somewhat on the shape of the endotherm and possibly on other factors related to the geometry of the sample and experimental conditions. The isothermal temperature

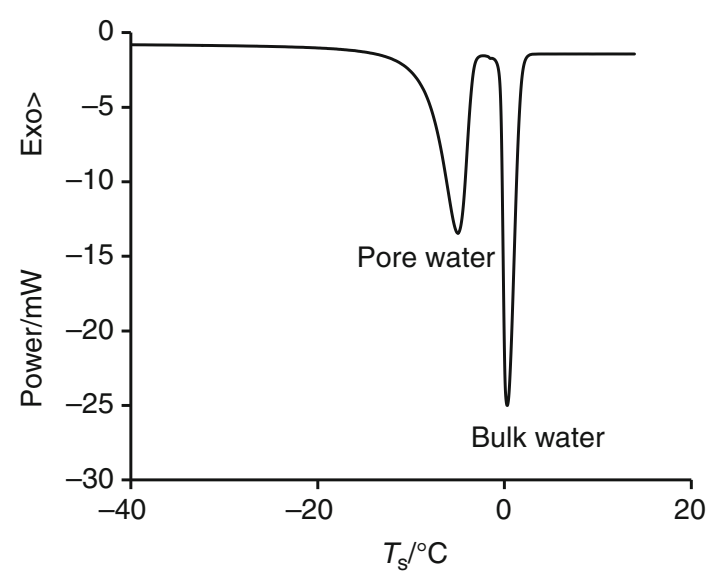

Fig. 7 The melting of water imbibed in silica15. Dynamic program, $\beta=5{ }^{\circ} \mathrm{C} \min ^{-1}$

depends principally on the operation of the sensor and controller. As Table 1 shows, the temperature precision from step melting is likely to be higher than from a melting onset determination.

Pore volume measurement

The procedure for determining the amount of melting water as a function of $T_{\mathrm{m}}$ will be illustrated for silica15. The dynamic endotherm for silica15 was first determined. This is shown in Fig. 7. The sample was then measured with a step program. The results from the step measurements after smoothening and correcting the baseline are shown in Fig. 8. The baseline is corrected to account for bow and drift and deviations of the isothermal baselines from the true $0 \mathrm{mw}$ baseline (see Fig. 4 for an example of an uncorrected baseline). Smoothening and baseline correction were done with the instrument's software.

An integration of the step endotherm as a function of time gives the total enthalpy function over the range of the experiment. This includes the melting enthalpy and the contribution of sensible heat. Therefore,

$H_{\mathrm{t}}=H_{\mathrm{s}}+H_{\mathrm{m}}$,

where $H_{\mathrm{t}}$ is the total enthalpy in $\mathrm{J}, H_{\mathrm{s}}$ in sensible heat in $\mathrm{J}$, and $H_{\mathrm{m}}$ is the melting enthalpy in J.The sensible heat for a given step is:

Table 1 Effect of $\beta$ in a step program on the specific melting enthalpy $H_{\mathrm{m}}^{\prime}$ and the final melting temperature $\left(T_{\mathrm{c}}\right)$ for distilled water. The onset melting temperatures $\left(T_{\text {onset }}\right)$ and $H_{\mathrm{m}}^{\prime}$ for the same samples measured with a dynamic program $\left(\beta=5{ }^{\circ} \mathrm{C} \min ^{-1}\right.$ are also shown)

\begin{tabular}{|c|c|c|c|c|}
\hline$\beta /{ }^{\circ} \mathrm{C} \mathrm{min}{ }^{-1}$ step & $T_{\mathrm{c}} /{ }^{\circ} \mathrm{C}$ step & $T_{\text {onset }}{ }^{\circ} \mathrm{C}$ dynamic & $H_{\mathrm{m}}^{\prime} / \mathrm{J} \mathrm{g}^{-1}$ step & $\overline{H_{\mathrm{m}}^{\prime} / \mathrm{J} \mathrm{g}^{-1} \text { dynamic }}$ \\
\hline 0.02 & 0.02 & -0.14 & -344 & -346 \\
\hline 0.10 & 0.02 & -0.27 & -336 & -339 \\
\hline 0.50 & 0.00 & -0.32 & -343 & -348 \\
\hline 2.00 & 0.00 & -0.34 & -339 & -345 \\
\hline
\end{tabular}




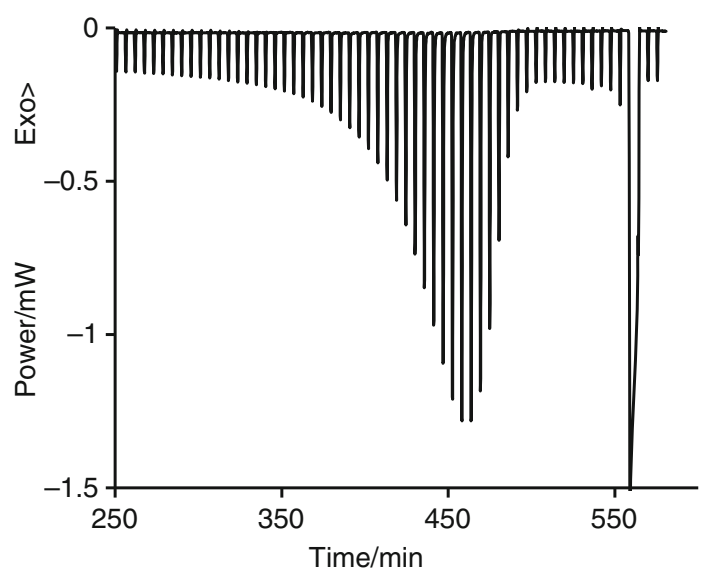

Fig. 8 Silica15 measured with a step program

$H_{\mathrm{s}}=m \cdot c_{\mathrm{p}} \cdot \beta \cdot \Delta t$,

where $m$ is the sample mass $\mathrm{kg}$ and $c_{\mathrm{p}}$ is its specific heat in $\mathrm{J} \mathrm{kg}^{-1}{ }^{\circ} \mathrm{C}^{-1}$, and $\Delta t$ is the time of the dynamic segment in $\mathrm{min}$. If a constant step interval is used, then it is reasonable to approximate $H_{\mathrm{s}}$ as a linear function over the melting transition. This approximation is best for melting transitions, which occur over a narrow temperature range. $H_{\mathrm{s}}$ can be calculated by measuring with a step program from a point well below the lowest temperature which melting occurs to a point past the melting transition and then drawing a line tangent to the $H_{\mathrm{t}}$ plot. This is shown in Fig. 9. $H_{\mathrm{m}}$ is found by subtracting $H_{\mathrm{s}}$ from $H_{\mathrm{t}}$.

The value of $H_{\mathrm{m}}$ used to make the melting water plot is taken at end of the isothermal step (after subtraction of the curves). This is shown in the insert in Fig. 9. The amount of pore water may be directly calculated from the enthalpy data if changes to $H_{\mathrm{m}}^{\prime}$ and $c_{\mathrm{p}}$ over the experiment are ignored, as shown in Fig. 10 and Table 2. Inspection of the pore

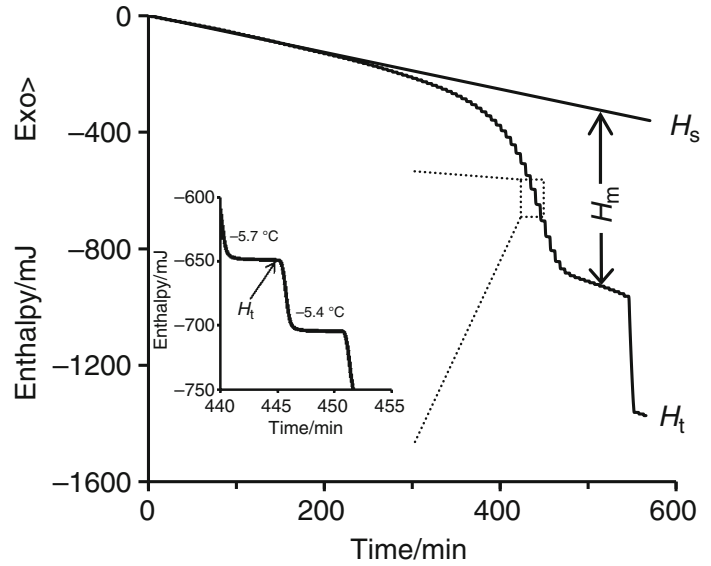

Fig. 9 The enthalpy plot for silica15 calculated by integrating Fig. 8. The enthalpy due to melting $H_{\mathrm{m}}$ is given by the total enthalpy, $H_{\mathrm{t}}$ minus the sensible heat, $H_{\mathrm{s}}$. The inset shows that the enthalpy values at the end of the isothermal segment are taken, after subtraction of the curves, to make the melting water plot (Fig. 10)

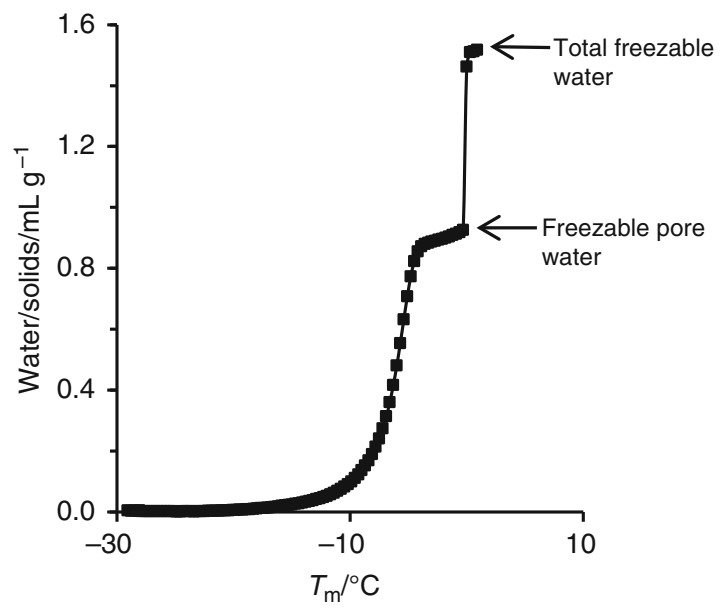

Fig. 10 Melting plot for silica15 showing the melting of both pore and bulk water. The quantity of nonfreezing water must be included to determine the total pore volume

volumes and calculated versus real moisture contents presented in Table 2 show that accurate pore volumes are obtained without accounting to variation of $H_{\mathrm{m}}^{\prime}$ and $c_{\mathrm{p}}$ with temperature. It is assumed in Fig. 10 that $T_{\mathrm{s}}=T_{\mathrm{m}}$ at the end of each isothermal segment. In Fig. 10, the freezable water in pores is given by the first plateau and the total freezable water in the sample is given by the second plateau.

One advantage of the step procedure is that it can provide excellent resolution of peaks because very small precise changes to $T_{\mathrm{m}}$ can be made. For example, consider the samples shown in Fig. 11. The silica4 and CPG12 samples have peaks, which are cleanly separated from the bulk water peaks and could be evaluated by direct peak integration. However, for the CPG35 and TMP samples, the pore and bulk water peaks overlap and cannot be directly evaluated.

Figure 12 shows that the pore volume of the CPG35 sample can be evaluated with the stepping procedure. In Fig. 12, the silica4 sample has a much broader PSD and therefore gives rise to a melting plot spread over a greater range than CPG35. It was found that the CPG100 was the sample in the series with the largest pore size whose porosity could be cleanly established with the stepping procedure. This is shown in Fig. 13. The CPG200 and CPG300 have so little melting temperature depression that the melting of pore and bulk water overlap. As Fig. 13 shows, the CPG200 sample does not reach a plateau before the melting of the bulk water occurs. The pore volumes of the CPG200 and CPG300 samples can be estimated by measuring $H_{\mathrm{m}}$ at $-0.1{ }^{\circ} \mathrm{C}$ since bulk water melting is still insignificant at this temperature. However, this approach cannot determine the volume of pores large enough that they cause $<0.1{ }^{\circ} \mathrm{C}$ melting temperature depression. The needed parameters of a step program depend on the PSD of the sample in question. The parameters used for the samples measured in this study are shown in Table 3. 
Table 2 Summary of pore measurements

\begin{tabular}{|c|c|c|c|c|c|c|c|c|c|c|}
\hline \multirow[t]{2}{*}{ Sample $\downarrow$} & \multicolumn{4}{|c|}{ Pore volume $/ \mathrm{mL} \mathrm{g}^{-1}$} & \multicolumn{2}{|c|}{ Moist. con./mL g ${ }^{-1}$} & \multirow[t]{2}{*}{$\mathrm{SA} / \mathrm{m}^{2} \mathrm{~g}^{-1}$} & \multirow[t]{2}{*}{$\mathrm{NFW} / \mathrm{mL} \mathrm{g}^{-1}$} & \multirow[t]{2}{*}{ Aver. $T_{\mathrm{m}} /{ }^{\circ} \mathrm{C}$} & \multirow[t]{2}{*}{ Av. $\mathrm{Hg} D / \mathrm{nm}$} \\
\hline & $\mathrm{N}_{2}$ & $\mathrm{Hg}$ & FSP & DSC & DSC & Direct & & & & \\
\hline silica4 & 0.60 & 0.55 & 0.57 & 0.57 & 1.19 & 1.06 & 585 & 0.23 & -18.8 & \\
\hline silica6 & 0.75 & 0.67 & 0.71 & 0.70 & 1.30 & 1.16 & 432 & 0.20 & -15.4 & \\
\hline silica10 & 1.10 & 0.99 & 1.02 & 0.97 & 1.61 & 1.55 & 323 & 0.13 & -7.92 & \\
\hline silica15 & & 1.07 & 1.11 & 1.01 & 1.62 & 1.64 & 282 & 0.10 & -6.57 & \\
\hline CPG7.5 & & 0.53 & & 0.47 & & 0.81 & 140 & 0.09 & -8.00 & 7.50 \\
\hline CPG12 & & 0.94 & & 0.81 & & 1.18 & 141 & 0.07 & -3.90 & 12.8 \\
\hline CPG17 & & 1.03 & & 0.95 & & 1.38 & 113 & 0.07 & -2.86 & 18.2 \\
\hline CPG24 & & 1.07 & & 0.97 & 1.40 & 1.38 & 79 & 0.06 & -1.94 & 23.7 \\
\hline CPG35 & & 1.04 & & 1.05 & 1.46 & 1.43 & 68 & 0.06 & -1.34 & 34.3 \\
\hline CPG50 & & 0.98 & & 1.01 & 1.39 & 1.35 & 44 & 0.04 & -0.86 & 50.7 \\
\hline CPG70 & & 2.43 & & 2.42 & 2.60 & 2.58 & 67 & 0.06 & -0.55 & 63.8 \\
\hline CPG100 & & 1.57 & & 1.53 & 1.74 & 1.75 & 25 & 0.02 & -0.36 & 104 \\
\hline CPG200 & & 1.31 & & 1.36 & 1.60 & 1.59 & 9.7 & 0.02 & -0.19 & 219 \\
\hline CPG300 & & 1.10 & & 1.12 & 1.86 & 1.81 & 7.4 & 0.04 & -0.14 & 315 \\
\hline
\end{tabular}

The average melting temperature from DSC and average diameter from $\mathrm{Hg}$ intrusion are shown in the last two columns

$S A$ Surface area measured with BET method, $N F W$ nonfreezing water

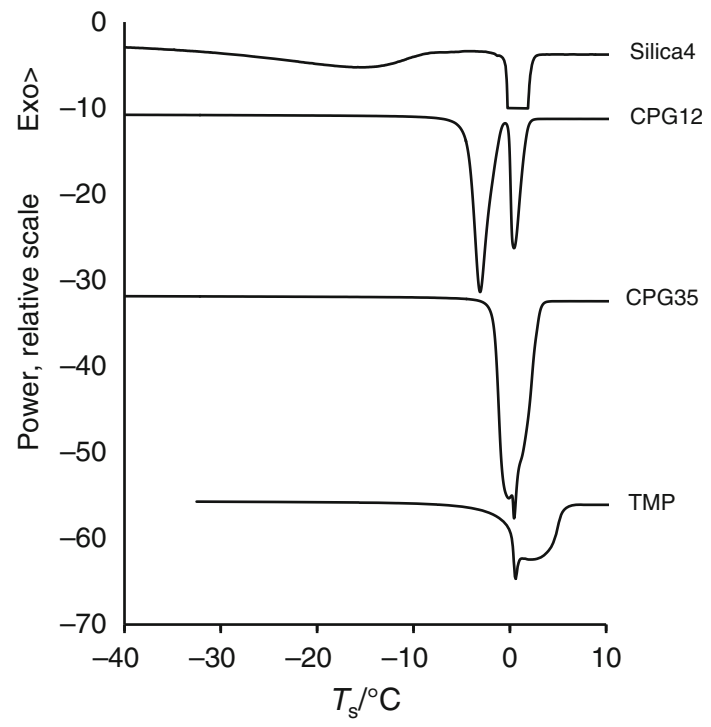

Fig. 11 Dynamic melts $\left(\beta=5{ }^{\circ} \mathrm{C} \min ^{-1}\right)$ for three porous glasses and TMP pulp

In Fig. 14, the pore volumes determined from thermoporosimetry show good agreement with the pore volumes determined from $\mathrm{Hg}$ intrusion for the entire range of glass samples. The pore volume from thermoporosimetry includes the nonfreezing water, whose measurement is described below. Even for the samples where the pore water and bulk water melting overlapped, CPG200 and CPG300, the pore volume could be accurately determined.

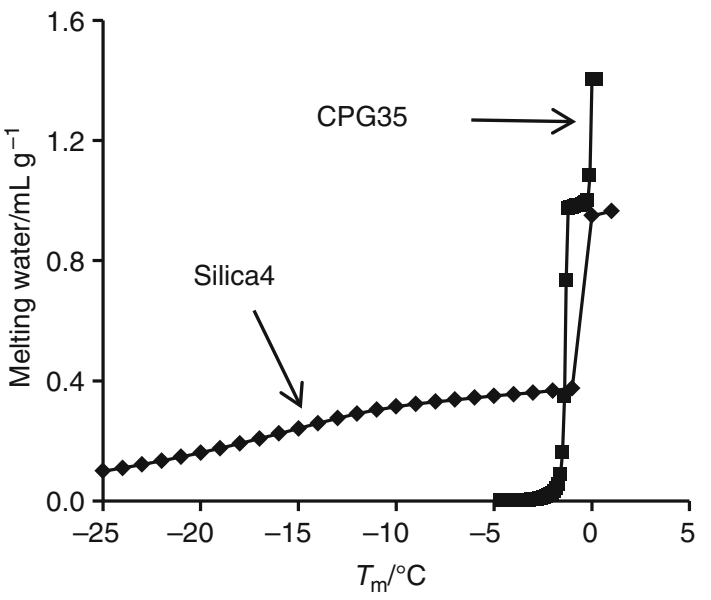

Fig. 12 Melting plots for two glass samples (freezable water only). The water in pores is cleanly resolved (first plateau) from the water outside the particles (second plateau)

\section{Measurement of the PSD}

In order to derive the PSD from melting water data, two further steps are required. Some quantity of vicinal water near the pore wall does not freeze [21,22]. The thickness of the nonfreezing water layer $t_{\mathrm{NFW}}$ must be calculated, and the relationship between pore diameter and melting temperature depression must be established. The quantity of nonfreezing water was calculated by subtracting the total amount of freezable water, calculated from the total melting enthalpy, from the moisture content of the sample. Although, the 


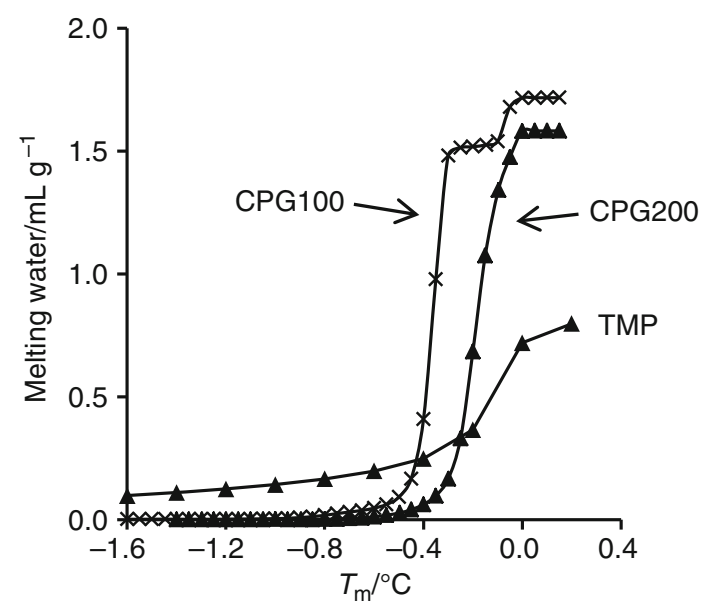

Fig. 13 The melting plots (freezable water only) of pulp fibers and some glass samples with relatively large pores. The CPG100 is the sample in the series with the largest pores, which can still be cleanly resolved (reach a plateau prior to the bulk water melting) with step melting

moisture contents are determined gravimetrically, it is assumed that the density of NFW is $1 \mathrm{~g} \mathrm{~mL}^{-1}$. Therefore, NFW amounts are expressed in $\mathrm{mL} \mathrm{g}^{-1}$ of solids. The NFW for the glass samples is plotted against the BET surface area in Fig. 15. From the slope, $t_{\mathrm{NFW}}$ is calculated as $0.35 \mathrm{~nm}$, which is close to a monolayer $(0.30 \mathrm{~nm})$. From the plot of known pore diameter versus $\Delta T \mathrm{~m}^{-1}$, shown in Fig. 16, $k$ is found to be $42 \mathrm{~nm}{ }^{\circ} \mathrm{C}$.

The derivative PSD for silica15 from thermoporosimetry and from $\mathrm{Hg}$ porosimetry is shown in Fig. 17. Good

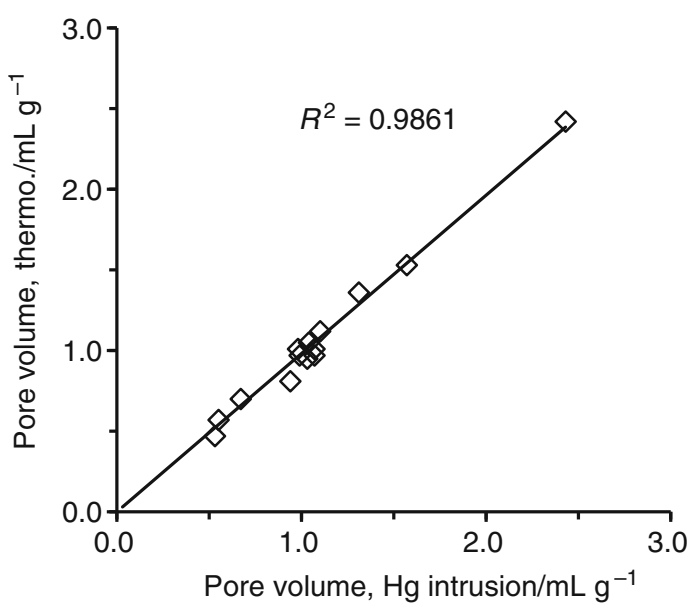

Fig. 14 The pore volume from thermoporosimetry (including freezing and nonfreezing water) versus that from $\mathrm{Hg}$ porosimetry for the CPG samples

agreement between the techniques is observed. Thus, for ridged mesoporous materials, the isothermal step melting technique can be used to accurately measure pore volume and sizes.

Measurement of cellulosic materials

The application of thermoporosimetry to cellulosic materials takes some further consideration. In Fig. 13, it can be observed that the melting transition of TMP is spread out over a wide range, but most of the melting happens close to $0{ }^{\circ} \mathrm{C}$. A good way to handle this situation is to use a

Table 3 Conditions for thermoporosimetric measurements

\begin{tabular}{|c|c|c|c|c|}
\hline Sample & Temp. range $/{ }^{\circ} \mathrm{C}$ & $\Delta T /{ }^{\circ} \mathrm{C}$ & $\beta /{ }^{\circ} \mathrm{C} \min ^{-1}$ & $t_{\text {iso }} / \mathrm{min}$ \\
\hline silica4 & -60.0 to 1.0 & 1.0 & 0.5 & 5 \\
\hline silica6 & -60.0 to 1.0 & 1.0 & 0.5 & 5 \\
\hline silica10 & -40.0 to 1.0 & 0.5 & 0.5 & 5 \\
\hline silica15 & -30.0 to 1.0 & 0.3 & 0.5 & 5 \\
\hline CPG7.5 & -17.0 to -5.0 & 0.2 & 0.2 & 5 \\
\hline CPG12 & -10.0 to -2.0 & 0.2 & 0.2 & 5 \\
\hline CPG17 & -9.0 to -1.0 & 0.2 & 0.2 & 5 \\
\hline CPG24 & -9.0 to -0.4 & 0.2 & 0.2 & 5 \\
\hline CPG35 & -5.0 to -0.2 & 0.1 & 0.2 & 10 \\
\hline CPG50 & -5.0 to -0.2 & 0.1 & 0.2 & 10 \\
\hline CPG70 & -2.5 to -0.1 & 0.05 & 0.2 & 10 \\
\hline CPG100 & -2.0 to -0.1 & 0.05 & 0.2 & 10 \\
\hline CPG200 & -1.5 to -0.1 & 0.05 & 0.2 & 12 \\
\hline CPG300 & -1.5 to -0.1 & 0.05 & 0.2 & 12 \\
\hline BHW and nanocellular & -33 to -0.1 & Varied & 0.2 & 5 \\
\hline $\mathrm{Hg}$ & -39.0 to -38.4 & 0.02 & 0.01 & 5 \\
\hline $\mathrm{H} 2 \mathrm{O}$ & -0.10 to 0.04 & 0.02 & 0.01 & 15 \\
\hline
\end{tabular}

$\Delta T=$ step interval, $\beta=$ dynamic segment heating rate, $t_{\text {iso }}=$ time of isothermal segment 


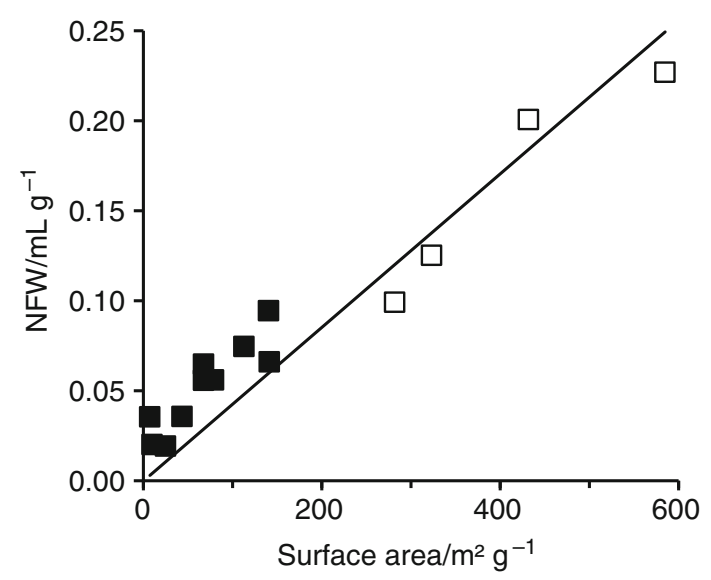

Fig. 15 The nonfreezing water versus surface area of the silica (open square) and CPG (filled square) samples

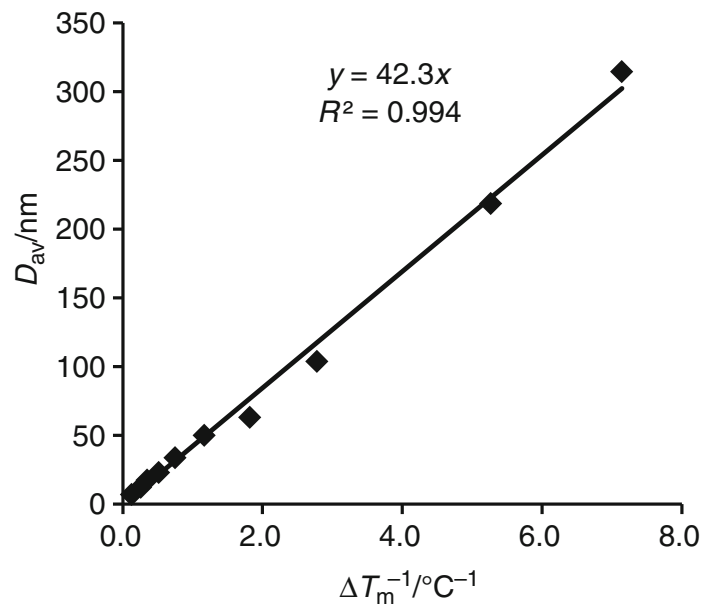

Fig. 16 Pore diameter from mercury porosimetry versus $\Delta T_{\mathrm{m}}^{-1}$ for the CPG samples

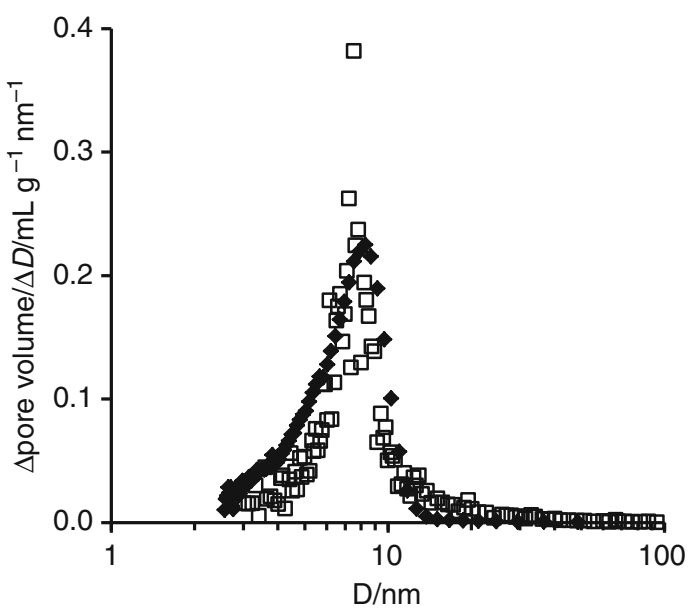

Fig. 17 The PSD from thermoporosimetry (filled square) and from $\mathrm{Hg}$ intrusion (open square) for silica15 nonlinear program. Ordinarily for cellulosic materials, we use steps of $-33,-20,-17,-14,-11,-7,-5,-3.5,-$ $2.5,-1.6,-0.8,-0.4,-0.2,-0.1{ }^{\circ} \mathrm{C}$. The first step is at low enough temperature that no melting occurs, and it is used to determine the sensible heat of the sample, $H_{\mathrm{s}}$. This is then subtracted from each subsequent step, taking into account the size of the step as described in Eq. 4, to determine the $H_{\mathrm{m}}$. After this, pore volume and nonfreezing water can be determined as described above.

This technique has been used by several research groups $[4,12]$ and has proven a useful way to analyze the pore structure of cellulosic materials. Up to the present, the value of $k\left(42 \mathrm{~nm}{ }^{\circ} \mathrm{C}\right)$ determined from the porous glass samples has been applied to calculation of pore size. However, it is clear that this leads to pore sizes that are too large compared with other methods. For example, in Kraft pulp fibers, NMR and solute exclusion have found that the largest pores are about 10-30 nm [23, 24]. The PSD from thermoporosimetry, up to $-0.1{ }^{\circ} \mathrm{C}(=430 \mathrm{~nm})$, still only covers the lower part of the distribution. The largest pores in Kraft pulp fibers are not detected with thermoporosimetry, and the pore volume from thermoporosimetry is substantially lower than from solute exclusion, as shown in Table 4. The calculated pore size using a value of $k=42 \mathrm{~nm}{ }^{\circ} \mathrm{C}$ is clearly erroneous for cellulosic materials.

Table 4 Pore measurements from two methods for the BHW and MFC samples

\begin{tabular}{lllll}
\hline Sample & Method & $\begin{array}{l}\text { Pore volume/ } \\
\mathrm{mL} \mathrm{g}^{-1}\end{array}$ & Av. D/nm & $\begin{array}{l}\text { Av. } \\
\Delta T_{\mathrm{m}} /{ }^{\circ} \mathrm{C}\end{array}$ \\
\hline BHW & Solute Ex. & 1.70 & 7.5 & \\
BHW & Thermopor. & 1.01 & & \\
MFC & Solute Ex. & 1.61 & 1.4 & \\
MFC & Thermopor. & 1.50 & & 0.85 \\
\hline
\end{tabular}

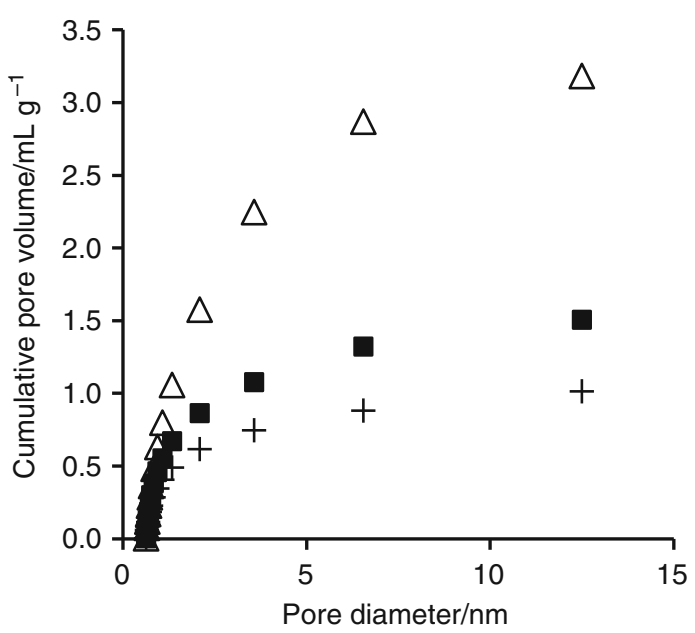

Fig. 18 The cumulative PSD for three cellulosic samples is shown. BHW pulp fibers (+), MFC (square), and NFC (triangle) 
Recently, the PSD for the MFC sample used in this study was determined by solute exclusion [19]. Since the pores in this sample are small enough that they are nearly completely covered by a thermoporosimetric measurement, a new value of $k$, applicable to cellulosic materials, can be calculated. From the data in Table $4, k$ is calculated to be $1.22 \mathrm{~nm}{ }^{\circ} \mathrm{C}$, which is significantly lower than the $42 \mathrm{~nm}{ }^{\circ} \mathrm{C}$ applicable to porous glass materials. In the calculation, the influence of the NFW layer is ignored since its thickness for cellulosic materials is still unclear.

Using $k=1.22 \mathrm{~nm}{ }^{\circ} \mathrm{C}$, the PSD for three cellulosic samples was measured. The PSD results in Fig. 18 appear reasonable. NFC has the highest swelling, followed by MFC and BHW [14]. For the sample of BHW, the PSD in Fig. 18 shows only the smaller pores in the fiber. The larger pores from 15 to $30 \mathrm{~nm}$ [19], detectable with solute exclusion, are outside the range of the thermoporosimetry measurement. For the nanocellulose samples, the thermoporosimetry measurement is expected to cover all or most of the pores within the particle itself, but exclude the pores between the fibrils. Thus, the technique gives a good way to measure the particle level swelling of nanocelluloses.

More research is needed to understand why different types of materials require different values of $k$ and also to determine the Gibbs-Thomson coefficient for various types of cellulosic materials. Furthermore, it still has not been confirmed that the value of $t_{\mathrm{NFW}}$ found for silica samples is valid for cellulose. This is especially interesting, as it may be possible to use NFW as a way to measure the hydrated surface area of cellulosic materials. This is a subject of the author's current research.

\section{Conclusions}

Isothermal step melting was shown to be an accurate and convenient way to measure the PSD of hard porous materials with pores up to $430 \mathrm{~nm}$. The method can also be applied to swollen cellulosic materials, but additional considerations need to be taken into account. For a sample of MFC, a Gibbs-Thomson coefficient of $k=1.22 \mathrm{~nm}{ }^{\circ} \mathrm{C}$ was calculated. Using this value of $k$, pores in cellulosic materials in the size range of about $1-12 \mathrm{~nm}$ can be measured.

Acknowledgements The author would like to thank the Finnish Academy for providing funding for this research.

Open Access This article is distributed under the terms of the Creative Commons Attribution License which permits any use, distribution, and reproduction in any medium, provided the original author(s) and the source are credited.

\section{References}

1. Landry MR. Thermoporometry by differential scanning calorimetry: experimental considerations and applications. Thermochim Acta. 2005;433:27-50.

2. Ishikiriyama K, Todoki M, Motomura K. Pore size distribution (PSD) measurements of silica gels by means of differential scanning calorimetry I. Optimization for determination of PSD. J Colloid Interface Sci. 1995;171:92-102.

3. Gane PA, Ridgway CJ, Lehtinen E, Valiullin R, Furo I, Schoelkopf J, Paulapuro H, Daicic J. Comparison of NMR cryoporometry, mercury intrusion porosimetry, and DSC thermoporosimetry in characterizing pore size distributions of compressed finely ground calcium carbonate structures. Ind Eng Chem Res. 2004;43:7920-7.

4. Borrega M, Kärenlampi PP. Cell wall porosity in Norway spruce wood as affected by high-temperature drying. Wood Fiber Sci. 2011;43:206-14.

5. Ishikiriyama K. Use of the melting point depression of ice for determination of the pore size in hollow fiber membranes of artificial kidney. Netsu Sokutei (Calorim Therm Anal) (Jpn). 1991;18:229-31.

6. Ishikiriyama K, Todoki M, Kobayashi T, Tanzawa H. Pore size distribution measurements of poly (methyl methacrylate) hydrogel membranes for artificial kidneys using differential scanning calorimetry. J Colloid Interface Sci. 1995;173:419-28.

7. Kaewnopparat S, Sansernluk K, Faroongsarng D. Behavior of freezable bound water in the bacterial cellulose produced by Acetobacter xylinum: an approach using thermoporosimetry. Aaps PharmSciTech. 2008;9:701-7.

8. Nedelec J, Grolier JE, Baba M. Thermoporosimetry: a powerful tool to study the cross-linking in gels networks. J Sol Gel Sci Technol. 2006;40:191-200.

9. Wheeler JL. Thermoporosimetry of polyacrylamide gels: characterization of pore size. In: The 2008 annual meeting.

10. Ishikiriyama K, Todoki M. Pore size distribution measurements of silica gels by means of differential scanning calorimetry II. Thermoporosimetry. J Colloid Interface Sci. 1995;171:103-11.

11. Grönqvist S, Hakala TK, Kamppuri T, Vehviläinen M, Hänninen T, Liitiä T, Maloney T, Suurnäkki A. Fibre porosity development of dissolving pulp during mechanical and enzymatic processing. Cellulose. 2014. doi:10.1007/s10570-014-0352-x.

12. Aarne N, Kontturi E, Laine J. Influence of adsorbed polyelectrolytes on pore size distribution of water swollen biomaterial. Soft Matter. 2012;8:4740-9.

13. Maloney TC, Paulapuro $\mathrm{H}$. The formation of pores in the cell wall. J Pulp Paper Sci. 1999;25:430-6.

14. Dimic-Misic K, Puisto A, Gane P, Nieminen K, Alava M, Paltakari J, Maloney T. The role of MFC/NFC swelling in the rheological behavior and dewatering of high consistency furnishes. Cellulose. 2013;20:2847-61.

15. Saito T, Kimura S, Nishiyama Y, Isogai A. Cellulose nanofibers prepared by TEMPO-mediated oxidation of native cellulose. Biomacromolecules. 2007;8:2485-91.

16. Eichhorn SJ. Cellulose nanowhiskers: promising materials for advanced applications. Soft Matter. 2011;7:303-15.

17. Isogai A, Saito T, Fukuzumi H. TEMPO-oxidized cellulose nanofibers. Nanoscale. 2011;3:71-85.

18. Larsson M, Zhou Q, Larsson A. Different types of microfibrillated cellulose as filler materials in polysodium acrylate superabsorbents. Chin J Polym Sci (Engl Ed). 2011;29:407-13.

19. Manninen MA, Nieminen K, Maloney TC. The swelling and pore structure of microfibrillated cellulose. In: I'Anson SI (Ed.), Advances in pulp and paper research, Cambridge. Pulp and Paper Fundamental Research Society: UK; 2013; 2:765-799. 
20. Stone JE, Scallan AM. A structural model for the cell wall of water swollen wood pulp fibers based on their accessibility to macromolecules. Cellul Chem Technol. 1968;2:343.

21. Nakamura K, Hatakeyama T, Hatakeyama H. Studies on bound water of cellulose by differential calorimetry. Text Res J. 1981;51:607-13.

22. Derjaguin BV, Churaev NV, Kiseleva OA, Sobolev VD. Evaluation of the thickness of nonfreezing water layer films from the measurement of thermocrystallization and thermocapillary flows. Langmuir. 1985;3:631-4.
23. Larsson PT, Svensson A, Wågberg L. A new, robust method for measuring average fibre wall pore sizes in cellulose I rich plant fibre walls. Cellulose. 2013;20:623-31.

24. Stone J, Scallan A. The effect of component removal upon the porous structure of the cell wall of wood. II. swelling in water and the fiber saturation point. Tappi J. 1967;50:496-501. 